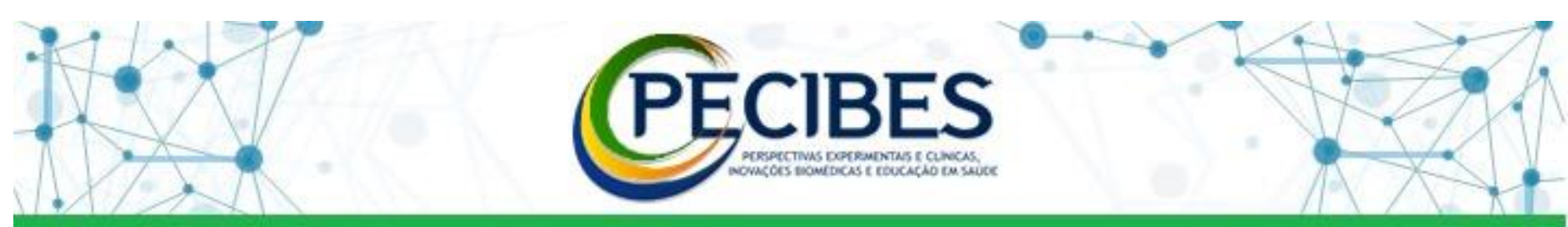

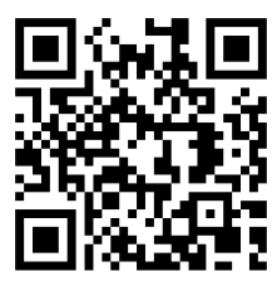

http://www.seer.ufms.br/in dex.php/pecibes/index

\begin{abstract}
* Autor correspondente: Gianfranco Sganzerla, Universidade Federal de Mato Grosso do Sul - UFMS. E-mail do autor: gianfranco.sganzerla @ufms.br
\end{abstract}

Descritores: Atletas. Rendimento atlético. Ansiedade.

\section{Diferença de força de preensão manual e potência dos membros inferiores conforme o nível de ansiedade em atletas.}

Gianfranco Sganzerla ${ }^{1}$, Silvio Assis de Oliveira-Junior ${ }^{2}$, Daniel Trainá Gama ${ }^{3}$, Fabricio César de Paula Ravagnani ${ }^{4}$, Felipe Eliezer Ferreira Denarde ${ }^{4}$, Sander Fric Zanatto $^{5}$, Christianne de Faria Coelho Ravagnani ${ }^{6}$.

1. Profissional de Educação Física. Programa de Pós-Graduação em Saúde e Desenvolvimento na Região Centro-Oeste, UFMS, Campo Grande, Mato Grosso do Sul, Brasil.

2. Fisioterapeuta. Programa de Pós-Graduação em Ciências do Movimento, UFMS, Campo Grande, Mato Grosso do Sul, Brasil.

3. Profissional de Educação Física. Faculdade de Educação, UFGD, Dourados, Mato Grosso do Sul, Brasil.

4. Profissional de Educação Física. Programa de Pós-Graduação em Ciências do Movimento, UFMS, Campo Grande, Mato Grosso do Sul, Brasil.

5. Acadêmico do Curso de Educação Física. Faculdade de Educação, UFMS, Campo Grande, Mato Grosso do Sul, Brasil.

6. Profissional de Educação Física e Nutricionista. Programa de Pós-Graduação em Ciências

Introdução: A ansiedade afeta de várias formas a prática esportiva. No entanto, ainda não é totalmente conhecido seus impactos na força e potência dos membros inferiores de atletas. Objetivos: Verificar a diferença de força de preensão manual e potência dos membros inferiores conforme o nível de ansiedade em atletas e a relação entre ansiedade e essas variáveis. Material e métodos: O estudo foi aprovado pelo Comitê de Ética em Pesquisa com Seres Humanos do Hospital Júlio Müller (CAAE $n^{\circ}$ 49600315.0.0000.5541). Participaram do estudo 113 atletas (90 homens e 23 mulheres; $23,4 \pm 6,5$ anos; $73,7 \pm 15,9$ $\mathrm{kg} ; 174,1 \pm 10,1 \mathrm{~cm})$ de 10 esportes. Primeiramente, os atletas preencheram o Beck Anxiety Inventory (BAI). Trata-se de um questionário com 21 questões que avalia traços de ansiedade, com escores totais variando de 0 até 63 pontos. Após responderem o BAI, os atletas foram divididos em dois grupos conforme resultado do Questionário. O grupo 1 (G1, $\mathrm{n}=63)$ foram os que tiveram resultado igual ou menor que a mediana $(\leq 4)$; e o grupo $2(\mathrm{G} 2$, $\mathrm{n}=50$ ) os que tiveram resultado maior que a mediana $(>4)$. Em seguida, os atletas realizaram o teste de dinamometria manual e teste do salto vertical, testes que avaliam a força da preensão manual e potência dos membros inferiores, respectivamente. Adotou-se o teste de Kolgomorov-Smirnov para testar a normalidade dos dados, teste T independente de Student para avaliar o desempenho físico entre os grupos e correlação de Spearman para avaliar a relação entre o resultado do BAI e testes físicos. Um $p<0,05$ foi considerado significante. Resultados: O BAI teve resultados que variaram de 0 a 33 pontos (mediana 4). O G1

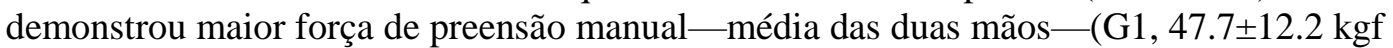
e $\mathrm{G} 2,41.6 \pm 13.0 \mathrm{kgf} ; \mathrm{p}<0,05)$ e potência dos membros inferiores $(\mathrm{G} 1,3726,9 \pm 916,1 \mathrm{~W}$ e $\mathrm{G} 2,3275,6 \pm 975,9 \mathrm{~W} ; \mathrm{p}<0,05)$ do que $\mathrm{G} 2$. O BAI teve correlação negativa com a força de preensão manual $(r=-0.24 ; p<0,05)$ e potência dos membros inferiores $(r=-0,25 ; p<0,05)$. Conclusão: Atletas menos ansiosos apresentaram maior força de preensão manual e potência dos membros inferiores. Apesar de pequena, a ansiedade apresenta relação negativa com essas duas variáveis. 